\title{
Unilateral Pectoralis minimus Muscle: A Case Report
}

\author{
Músculo Pectoralis Minimus Unilateral. Reporte de caso
}

\author{
Rajalakshmi Rai; Anu V. Ranade; Latha V. Prabhu; Prakash; Rajanigandha V. \& Soubhagya R. Nayak
}

\begin{abstract}
RAI, R.; RANADE, A. V.; PRABHU, L. V.; PRAKASH; RAJANIGANDHA, V. \& NAYAK, S. R. Unilateral Pectoralis minimus muscle. A case report. Int. J. Morphol., 26(1):27-29, 2008.

SUMMARY: Presence of additional muscles in the pectoral region has often been reported. We report about the presence of Pectoralis minimus muscle, in a male cadaver. It was present deep to the pectoralis major muscle and superomedial to the pectoralis minor muscle. The variant was closely related to the branches of thoracoacromial vessels where one of the branches was passing between the pectoralis minor muscle and the variant muscle. Hyperabduction of the arm may compress these vessels giving rise to certain vascular symptoms. Also these variations should be borne in mind during certain surgical procedures in the pectoral region.
\end{abstract}

KEY WORDS: Muscle variation; Anatomy, Pectoral muscles.

\section{INTRODUCTION}

The pectoral muscles connect the upper limbs to the thorax. There are several reports about the presence of aberrant muscles in the pectoral region (Turgut et al., 2000; Sawada et al., 1991; Bonastre et al., 2002; Arican et al., 2006, Bergman et al., 1988). Some investigators have reported about the presence of a Pectoralis minimus muscle lying between the first costal cartilage and the coracoid process (Testut, 1896). They state that the variant muscle was lying under the pectoralis major muscle and was medial to the pectoralis minor muscle. We report about the presence of a similar muscle, in a male cadaver, which was observed during routine dissection for undergraduates. Turgut $e t$ al. reported about the insertion abnormalities of Pectoralis minimus. Pectoralis quartus muscle, a thin muscle of triangular shape, was observed by Sawada et al. on the left thoracic wall of a male cadaver. The same authors also reported about the presence of Pectoralis intermedius muscle on the right thoracic wall of a female cadaver. A pectoralis quartus muscle and an unusual axillary arch were found on the left side of a female cadaver (Bonastre et al.).

\section{CASE REPORT}

During a routine dissection of upper limbs for undergraduate students, an aberrant muscle was observed on the right pectoral region of a male cadaver. It was present deep to the pectoralis major muscle and superomedial to the pectoralis minor muscle. An analysis of the literature reveals that this muscle resembles Pectoralis minimus muscle. The variant muscle originated from the 2 nd costal cartilage and becomes tendinous laterally. The tendon passes superficial to pectoralis minor muscle and gets inserted into the superior surface of coracoid process. The muscular part also receives some fibres from the clavicle along its medial side. The thoracoacromial vessels pass above the variant muscle and some branches of thoracoacromial vessels (TAa) pass between the minor and the variant.

\section{DISCUSSION}

Reports in the literature reveal that Pectoralis minimus muscle (sterno-costo-coracoidian muscle) is a rare muscle extending between the first costal cartilage and the coracoid process (Testut, 1896). The pectoral muscles develop from the pectoral premuscle mass (Lewis, 1910). This pectoral premuscle mass lies in the lower cervical region on the medial side of the arm bud. It is widely continuous with the arm premuscle sheath, and lies almost entirely anterior to the $1^{\text {st }}$ rib. In an 11-mm. embryo it reaches about the level of the 3rd rib, but the two muscles still form a single columnar

Department of Anatomy, Kasturba Medical College, Mangalore, India. 
mass attached to the humerus, to the coracoid process, and to the clavicular rudiment. As the mass differentiates, it flattens out and extends caudoventrally to the region of the distal ends of the upper ribs. The caudal end of the muscle extends near to the tip of the $5^{\text {th }}$ rib and the muscle begins to assume the adult form, with fibres arising from front of the upper five ribs and sternal angle as well as from the clavicle. At this stage the proximal portion of the muscle has split into the major and minor portions, the one attached by tendon to the humerus and the other to the coracoid process. Both muscles fuse together near the costal attachments. In a 16-mm embryo the two muscles are quite distinct, the pectoralis major now extending to the $6^{\text {th }}$ rib and showing a distinct cleavage between the costal and clavicular portions. The pectoralis minor muscle has now its distinct attachment to the $2^{\text {nd }}, 3^{\text {rd }}$, and 4 th ribs (Lewis). However, some endogenous and exogenous factors can cause total or partial agenesis of pectoral muscles or development of various abnormalities (Yamasaki, 1989). Turgut et al., (2000) reported about the presence of Pectoralis minimus muscle, similar to our case, on the left side. It took origin from the second costal cartilage to the manubrium of sternum and the second costochondral joint, afterwards became a tendinous structure and divided into two on the coracoid process. The thicker part ended on the upper surface of the articular capsule of the shoulder joint, the thinner part inserted on the lateral third of inferior part of clavicle and fascia of subclavius muscle. Sawada et al. report about the presence Pectoralis quartus muscle. They state that the pectoralis quartus originated from the rectus sheath, and joined the inferior medial border of the fibrous band of the axillary arch, at the lateral edge of the pectoralis major muscle.

Hyperabduction and lateral rotation of the shoulder may press excessive stretch on the neurovascular structures, thereby giving rise to neurological and vascular symptoms in the arm (Daskalakis, 1983). In our case, presence of branches of thoracoacromial vessels above and below the variant muscle may impinge the vessels during hyperabduction of the arm. This variation may cause pain during certain shoulder movements, because of compression of the vessels, and may lead to mechanical alterations in the muscular dynamics of the shoulder. Many investigators report a potential region, which is present in the insertion site of the pectoralis minor to the coracoid process, where the axillary artery can be compressed. Furthermore they report that the presence of a musculoskeletal abnormality may cause axillary artery compression and outlet compression syndrome (Karacagil \& Eriksson, 1987; Serpel \& Baum, 1991). Hence this muscular variation along with the involvement of vessels is clinically important because of its potentiality to restrict abduction of the arm.

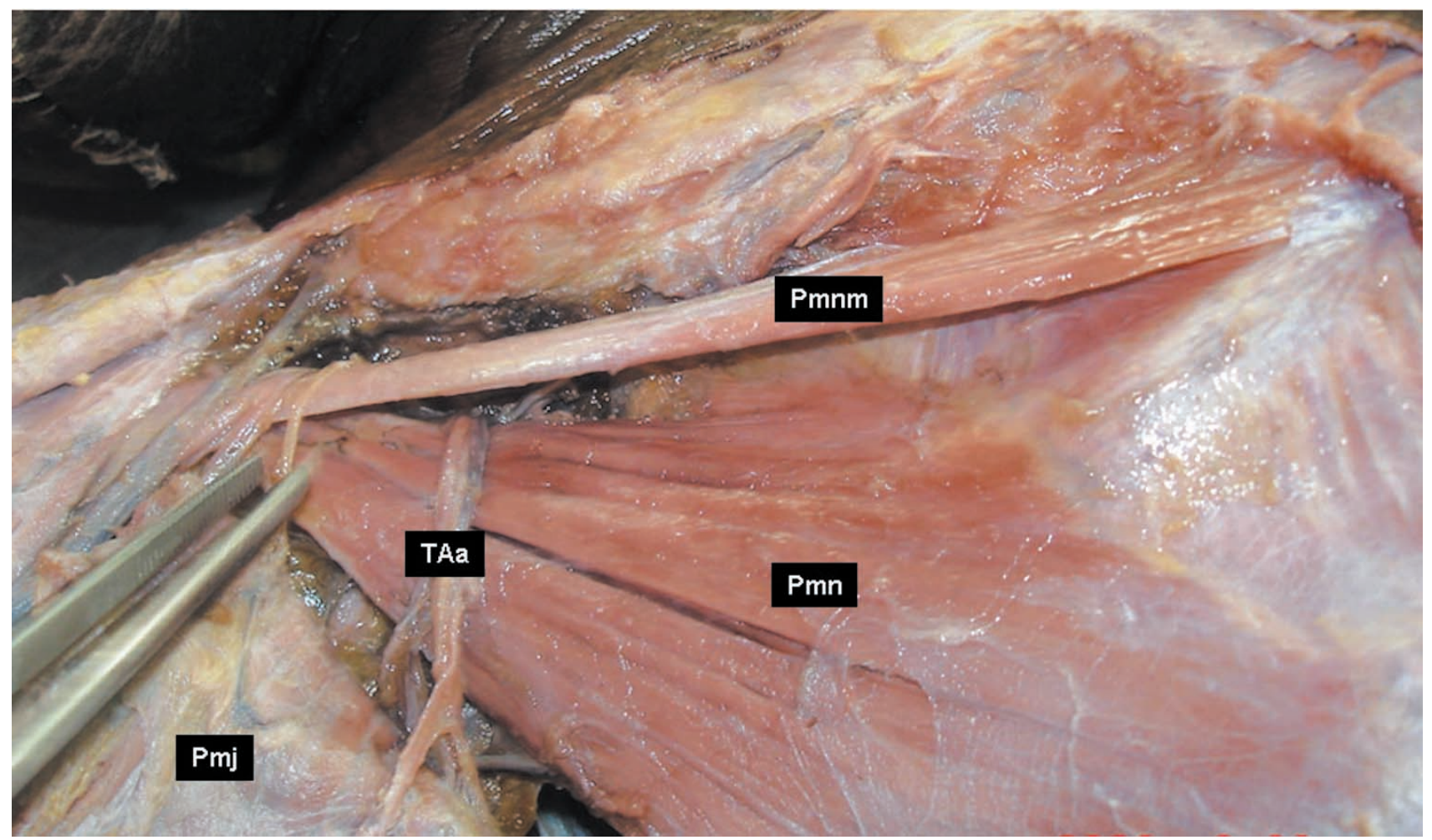

Fig. 1. Dissection of right pectoral region showing Pectoralis minimus muscle. Pmj. Pectoralis major muscle; 2. Pectoralis minor muscle; Pmnm. Pectoralis minimus muscle; TAa. Pectoral branch of thoracoacromial artery. 
RAI, R.; RANADE, A. V.; PRABHU, L. V.; PRAKASH; RAJANIGANDHA, V. \& NAYAK, S. R. Músculo Pectoralis minimus unilateral. Reporte de caso. Int. J. Morphol., 26(1):27-29, 2008.

RESUMEN: Presencia de músculos supernumerarios en la región pectoral han sido reportados. En un cadáver de un hombre se describe la presencia de un músculo Pectoralis minimus. El músculo se localizaba profundo al músculo pectoral mayor y superomedial al músculo pectoral menor. La variación se relacionaba con las ramas de los vasos toracoacromiales donde una de las ramas pasaba entre el músculo pectoral menor y la variación muscular. La hiperabducción del brazo puede comprimir estos vasos provocando síntomas vasculares. Estas variaciones se deben tener en cuenta durante los procedimientos quirúrgicos en la región pectoral.

PALABRAS CLAVE: Variación muscular; Anatomía; Músculos pectorales.

\section{REFERENCES}

Arican, R. Y.; Coskun, N.; Sarikcioglu, L.; Sindel, M. \& Oguz, N. Co-existence of the pectoralis quartus \& pectoralis intermedius muscles. Morphologie. 90(290):157-9, 2006.

Bergman, R. A.; Thompson, S. A.; Afifi, A. K. \& Saadeh, F. A. Compendium of Human Anatomic Variation. Munchen, Baltimore: Urban and Schwarzenberg, 1988.

Bonastre, V.; Rodriguez-Niedenfuhr, M.; Choi, D. \& Sanudo, J. R. Coexistence of a pectoralis quartus muscle and an unusual axillary arch: case report and review. Clin. Anat., 15(5):366-70, 2002.

Daskalakis, M. K. Thoracic outlet compression syndrome: current concepts and surgical experience. Int. Surg., 68:337-44, 1983.

Karacagil, S. \& Eriksson, L. Entrapment of the axillary artery by anomalous muscle. Acta Chir. Scand., 153:633-4, 1987.

Lewis, W. H. In Mall and Keibel's Manual of Human Embryology. Philadelphia, 1910. V. 1. p. 487.

Testut L. Traité d'Anatomie humaine. Doin Ed, Paris, 1896. V. 1. $487,725-8$.

Turgut, H. B.; Anil, A.; Peker, T. \& Barut, C. Insertion abnormality of bilateral pectoralis minimus. Surg. Radiol. Anat., 22(1):55-7, 2000.

Sawada, M.; Ishibashi, Y.; Suzuki, T. \& Chiba, S. Case reports on the pectoralis quartus and the pectoralis intermedius muscles. Kaibogaku Zasshi., 66(2):99-105, 1991.

Serpel, J. W, \& Baum, M. Significance of "Langer's axillary arch" in axillary dissection. Aust. N. Z. J. Surg., 61:3102, 1991 .
Yamasaki, M. Anatomical study on 2 cases of the congenital partial defect of pectoralis major and minor muscles. Anat. Anz., 168:423-32, 1989.

Correspondence to:

Rajalakshmi Rai

Senior Lecturer

Department of Anatomy

Center for Basic Sciences

Kasturba Medical College

Bejai, Mangalore

INDIA

Tel: 08242211746

Fax: 08242428183

E-mail: rajalakshmirai@yahoo.co.in

Received: 10-09-2007

Accepted: 22-10-2007 
